\title{
OVERT DEPENDENCE OF HEALTH INSURANCE INDUSTRY ON HEALTHCARE SYSTEM
}

\author{
V R Uma ${ }^{1 *}$ and V Ilango ${ }^{2}$ \\ ${ }^{1}$ Department of Commerce, School of Commerce, Finance and Accountancy, \\ Christ University, Bangalore 560029, India \\ ${ }^{2}$ Department of Computer Application, CMR Institute of Technology, \\ Bangalore 560037, India \\ *Corresponding author: uma.vr@christuniversity.in
}

Published online: 4 June 2021

To cite this article: Uma, V. R., \& Ilango, V. (2021). Overt dependence of health insurance industry on healthcare system. Asian Academy of Management Journal, 26(1), 197-219. https://doi.org/10.21315/aamj2021.26.1.8

To link to this article: https://doi.org/10.21315/aamj2021.26.1.8

\begin{abstract}
$A$ vast majority of the population in the developing economies remains uninsured. Moreover, the informal sector that employs a larger section of the society is untouched by any of the government scheme. In this study, we use health belief model to examine the factors that induce willingness to buy health insurance among the illness and the non-illness group. A cross-sectional study was conducted on 1,339 participants above 20 years of age of which 351 had contracted illness in the past and 988 had not. Data was collected using questionnaire from four highly populated districts in India. The questionnaire was developed based on the constructs of health belief model. The data was statistically analysed. Kendall's Tau-b correlation technique was used to explore the relationship between perceived vulnerability and product aversion. Logistic regression was used to find out the odds at which each independent variable, categorised based on the health belief model, contributes to willingness to buy. The model was able to predict $15 \%$ of the variance for willingness-to-buy among the illness and $27 \%$ among the nonillness groups. Findings suggest that the perceived vulnerability reduced product aversion among the illness group. Mere presence of primary and super-specialty hospitals was not sufficient for the illness group to subscribe for health insurance. Income perceptions emerged as a significant predictor among the illness group. Presence of well-established hospital, income perceptions, and subjective norms were significant predictors among the non-illness group. The growth of the health insurance industry largely depends upon the presence of well-established hospitals. In the absence of adequate healthcare facilities, attempts by the insurers to promote insurance covers will become futile. Insurers should

(C) Asian Academy of Management and Penerbit Universiti Sains Malaysia, 2021. This work is licensed under the terms of the Creative Commons Attribution (CC BY) (http://creativecommons. org/licenses/by/4.0/).
\end{abstract}


also consider alternate segmentation patterns albeit the present socio-demographic pattern, as the health risk experience differs among individuals.

Keywords: willingness to buy, healthcare, health belief model, health insurance, illness and non-illness

\section{INTRODUCTION}

In principle, it is the government's primary responsibility to ensure safe health for every citizen. With burgeoning population, developing economies like India find it very difficult to provide public healthcare facilities to all. It should be noted that any healthcare system must include primary, secondary, and tertiary services. Although the country provides these services, yet they are inadequate to meet the requirements of all the citizens. Looking back at the history, like any other country, India was predominantly dominated by government hospitals. Missionaries established private but not-for-profit hospitals in rural areas. Unfortunately, many of these mission hospitals found it difficult to survive amidst increased cost, unavailability of resources, etc. Hence, the health policy permitted establishment of private-for-profit hospitals but with a condition that certain proportion of their services such as allocation of beds should be reserved for the poor and needy. However, most of these private hospitals were established in cities. Among these, some were corporate hospitals and were in cosmopolitan and metropolitan cities. Apparently, the standard of living of people residing in these locations was good enough to afford expensive treatments. On the flip side, privatisation has increased the financial burden. It has made healthcare inaccessible for the economically backward class. It is also evidenced that these private hospitals unnecessarily increase cost by advising unwanted diagnostics. Despite the cost, private sector is highly preferred for treatment in both the urban and rural areas compared to the public hospitals due to lack of confidence on the latter (Sharma, 2018) and 70\% of the medical expenses are borne through out-of-pocket in India (John, 2010). Perhaps the highest compared to any other country.

Being a developing country, with vast majority of the population falling under the lower income strata, the situation is even more depressing for a household that has a single earning member. For instance, tuberculosis (TB) is one major disease that is causing a huge burden to the socioeconomic development of the household and the country as well. Around $20 \%$ of the population is affected by this disease and ironically it affects during the productive years. Unfortunately, due to inadequate infrastructure, containing this disease has become a major challenge. It cripples the family income leading to impoverishment (Sundaran, 2012). The treatment period for an adult diagnosed with TB is around three to 
four months. During the treatment period he/she incurs direct and indirect losses. Besides the treatment cost, which is the direct cost, other indirect costs such as loss of wage during the treatment period, transportation, and accommodation also adds to their woes. It should be noted that most of these healthcare facilities are located in towns and cities, therefore one has to travel to avail the treatment. Hence, the actual cost is the sum of the direct and the indirect expenses incurred. As most of the public healthcare services are situated in cities and towns and more than half the population in developing economies lives in rural areas, the issues of transportation and accommodation costs add to their burden. Undoubtedly, in rural areas there are healthcare centres but these are predominantly primary healthcare centres that are first referral points. They also provide maternity care. In this study, apart from seeking to find whether subscription to health insurance depends on the impact of presence or absence of primary care services, other broad categories such as super-specialty and multi-specialty healthcare services are also included. Super-specialty hospitals specialise either in one or certain disciplines such as orthopedics, oncology, cardiology, etc. Conversely, multi-specialty hospitals are the well-established ones that specialise in multiple or wide range of disciplines. Hence, the medical treatments are confined to only few diseases in super-specialty hospitals compared to the multi-specialty hospitals.

In the absence of a proper financing mechanism, to meet the medical costs they ended up borrowing from the unorganised financial institutions at higher interest rates which eventually leads to depletion of their resources in the future. Therefore, health episodes besides causing emotional disturbances also results in financial loss due to increased out-of-pocket (OOP) expenses. Absence of financial coping strategies can lead to adverse health outcomes, as they tend to delay or skip medication (Zhao et al., 2019). Globally, healthcare costs are skyrocketing due to several reasons such as rise in per capita income, technology infusion, growing elderly population (Barati \& Fariditavana, 2019), increase in chronic noncommunicable diseases, and privatisation of healthcare services (Gumber et al., 2017).

Although the Indian economy is progressive, yet its tax administration does not permit sufficient allocation towards healthcare expenditure. To finance healthcare, the tax to gross domestic product (GDP) ratio should be a minimum of $25 \%$. Further 5\% of the GDP contribution should be directed to healthcare expenditure. In India, the tax to GDP ratio is a little above $15 \%$ and only around $1.5 \%$ is directed to healthcare expenditure (Duggal, 2012). Visibly the tax base is very small to support universal health coverage. 


\section{VR Uma and VIlango}

Similar to other countries, India also offers health insurance as a part of social security schemes primarily covering the formal sector and the economically backward class, that are by and large non-contributory in nature (Tirgil et al., 2019). Unfortunately, in densely populated countries, larger proportion of the poor works in the informal sector leaving them inaccessible to any of these benefits (Fenny et al., 2018) despite its two-fifth contribution to GDP (Majumdar \& Borbora, 2013). Various schemes are offered by the central and state governments to cover the economically backward class although they may not be as extensive as commercial insurance. At times they may not be able to avail certain treatments as there are cost limits for coverage when a contingency arises. Further, there are limits in the number of members from a household that can avail the scheme during a particular year. When these limits are exceeded, they are left with no option except to continue to live with health risk (Lam et al., 2017).

Employers in the organised sectors tie up with private insurers and offer group insurance facilities to their employees. The policy is offered as a package for all the employees, which means the risk coverage will be the same. However, it should be noted that the risk exposure may not be the same for all. For instance, if an employee has a family history of heart disease, the probability of risk exposure will be comparatively high for this individual. In a group insurance, such exclusive coverage is not offered. Hence, along with the employer-sponsored insurance that offers only basic coverage, supplementary or top-up plans also should be availed for a comprehensive coverage. Such top-up plans is available at own cost and not covered by the employer. Therefore, whether an individual is covered by a social security scheme offered by the government or through employer-sponsored insurance in a private company, the coverage is inadequate; it is as good as staying uninsured. When an individual enrolls in an insurance contract that adequately covers the risk exposure, then he or she is said to be insured; this is possible only through voluntary insurance.

\section{Health Belief Model}

This model has been widely used in explaining various health related behaviours in healthcare such as medicine use among children (Bush \& Iannotti, 1990), impact of future use of mammography based on previous experience (Stein et al., 1992), coping during illness (Kirscht, 1974), attribution of cause regarding heart disease (King, 1983), HIV testing (Oyekale \& Oyekale, 2010), etc. Conversely, the model has also been used in other areas such as to examine the influence of religion in healthcare practices (Kirn, 1991), pesticide use (Khan, 2010; Raksanam et al., 2014), etc. Hence, it is evident that this model has been used extensively to examine the health behaviours in health and non-healthcare areas. 


\section{LITERATURE REVIEW}

In this study, the use of health belief model is advocated to understand the desire to buy insurance, as it is evidenced that insureds tend to stay healthier than the uninsureds, as they choose to adopt regular health checkups (Sung et al., 2008; Jung \& Streeter, 2015) hence, the chance of detection of disease at an earlier stage helps to mitigate risk. Subscription to health insurance should be considered as preventive and precautionary behaviour, ideally being the premise on which health belief models are constructed.

People are largely governed by their belief system, which is a product of inherent needs, motives, fears, goals, desires, and external factors such as cultural and social factors (Hochbaum, 1958). Beliefs lead to behavioural responses. According to Maiman and Becker (1974), decisions relating to health depend on ones perceived susceptibility, severity, and benefits.

\section{Perceived Susceptibility/Vulnerability}

Palm and Hodgson (1992) in their seminal work on property insurance argue that the attitude of the uninsureds changes on the happening of an unforeseen catastrophic event. They observed that post a major earthquake, the victimised, whose properties were damaged took property insurance. On the contrary, the nonvictimised who stayed a little away from the fault who did not suffer a severe damage did not change their attitude towards insurance. They still decided to stay uninsured as their aversion towards insurance continued. After the event, the victims perceived themselves to be more vulnerable. Hence, vulnerability depends on risk perception (Botzen et al., 2009). When there is a belief that the risk would occur in future due to which they would have to incur huge financial losses, then perhaps the inclination towards mitigation strategies would increase. Lin and Grace (2007) also find that as the perception on financial vulnerability increases the demand for insurance also increases. However, health belief model primarily constructed on the foundation of stimulus-response theory gives another dimension. The events that are confronted in day-to-day life act as stimuli and the responses lead to consequences eventually leading to behaviour (Cantania, 1984). Sometimes an individual is exposed to multiple stimuli in varying degrees such as mild to stronger health episodes. Under these circumstances, the degree of response to each of these stimuli may not be the same. It differs according to the varying degree of consequences. For instance, some of the health episodes can cause huge financial implication on the household and the rest may not. Behaviour occurs based on the response to a particular stimulus (Skinner, 1950). Therefore, how the stimulus itself is perceived determines the behaviour. Perception towards health 


\section{VR Uma and V Ilango}

risks determines the coping mechanism one would choose to adopt. Although one is aware of the fact that negative life events such as death or occurrence of chronic illness could have a devastating effect on the family, causing emotional stress, and heavy financial loss, yet they are by and large uncertain. There is always a tendency to underestimate negative events especially health risks (Branstrom et al., 2006). Perhaps some may develop optimistic bias or unrealistic pessimism. Either of these conditions leads to maladaptive behaviour. Optimistic bias is a condition in which self-risk is underestimated compared to others. Thus, they engage themselves in self-protective behaviours such as dieting and exercising believing that the exposure to health hazards can be minimised (Weinstein, 1989). On the contrary, in unrealistic pessimism, health risk is overestimated thus increasing fear and anxiety (Asimakopoulou et al., 2008). These negative emotions resist adoptive behaviours (Brown, 2007) as they lose motivation. Hence, it is evident that adoption of coping mechanisms varies based on perceived vulnerability. Feeling vulnerable does not guarantee subscribing for insurance. They adopt other self-protective strategies irrespective of the fact whether these measures are scientifically proven or not. Previous studies indicate that there is aversion to buy health insurance due to lack of awareness (Choudhary et al., 2013; Goel, 2014) despite their vulnerability. Hence, the present study hypothesises:

H1: Perceived financial vulnerability has an influence on aversion towards health insurance products among the illness and non-illness groups.

In this study, two groups have been identified to understand their perception towards vunerability and its impact on the purchase of voluntary health insurance. Illness group are those who confronted a severe health episode in the past and due to which they suffered huge financial crises. The non-illness group had either no or less exposure to illness episode in the past. Hence, this group did not experience financial burden in the past as the illness group.

\section{Perceived Severity}

It is a condition wherein one comprehends the consequences by not pursuing a desirable behaviour. The severity with which one perceives life events will vary depending upon the age, gender etc. Response to a stimulus such as health risk can also be compulsive (Islam et al., 2018) and depend upon socio-demographic factors like age, income, size of the household, education, and occurrences of similar stimuli in the past (Bagarinao, 2016).

Younger adults though uninsured tend to be healthy. The requirement of health cover will be less, provided they face health issues that aggravate risk. On the 
contrary, the older population is more susceptible to health risk. In the absence of health cover, deteriorating health can lead to financial loss and stress (Kirby \& Kaneda, 2010). Accordingly, the demand for health cover should be more from the older population than the younger adults. On the flip side, cognitive decline takes place as one grows older. Information seeking also reduces as they would want to rely on their personal experience. This could lead to undesirable choice (Yoon et al., 2005). In the past had they not been victimised with major illness then they might choose to stay uninsured. There is more dependence on the affect component. However, Yoon et al. (2009) find that as people grow older the ability to conserve mental energy increases. They rely more on heuristics. At the same time, they restrict themselves to detailed processing but develop strategies to eliminate alternatives that are not congruent as soon possible. However, young adults who are generally risk averse and have aging parents to take care, as a precautionary measure may plan to avail insurance. Risk attitudes are independent of demographic cohorts (Noussair et al., 2014).

The demand for health cover will be higher from the low-income group as they are more vulnerable to sickness due to poor standards of life. Conversely, they may not be willing to pay for health insurance due to their income level. Their ability to consume or purchase a private health cover may be insufficient. It should also be noted that as healthcare cost increases the premiums also increase thus making them unaffordable by the low-income group (Kaestner \& Lubotsky, 2016). On similar lines, given the high premium rates and uncertainty of exposure to risk, the higher income group also may choose to remain uninsured as they would want to invest their money on other financial instruments.

Developing economies are characterised by a vast majority of middle-income families. Apparently, the members in these households experience uncertainties in earnings as most of them are employed in private and informal sectors. As a matter of fact, when the uncertainty in earnings is more, precautionary savings will also increase (Mastrogiacomo \& Alessie, 2014). With rising medical costs, households are expected to save in precautionary financial instruments. However, Starr-McCluer (1996) find a weak relationship between earnings uncertainty and investment in precautionary savings such as insurance. Disruptions in marital life impacts women particularly due to dependency on the spouse's health cover. Separation or divorce invalidates the coverage. Post-separation women become uninsured. On the contrary, if the women are employed or highly educated, marital disruptions can cause own or self-coverage. Marital disruptions can cause a shift in the type of coverage from dependency to own (Peters et al., 2014). Nonetheless, a study by Pol et al. (2000) find that separations or divorce can equally impact the near elderly men too. Interestingly, even men remain uninsured post-marital 
disruption. Women being the primary care givers play a vital role in healthcare decisions of the family (Varkey et al., 2010) compared to men; they control the household expenditure as well. In this study we argue that purchase of health cover will depend on the socio-demographic profile.

$\mathrm{H} 2$ : Socio-demographic factors such as age, gender, income, and marital status affect purchase intention.

\section{Perceived Benefits}

The perceived benefits are the benefits where one cognizes that by contracting a particular behaviour, gain would outweigh the cost or the barriers. Hence, perceived benefits are measured through perceived barriers and costs.

\section{Perceived barriers}

The geographic location acts as a barrier. Localities with fewer or no healthcare facility are a deterrent to health insurance. Asgary et al. (2004) find negative relationship between localities that do not have healthcare facilities and willingness to purchase insurance. The more distant the facility, the lesser is the willingness to pay as they perceive that the benefits of insurance cannot be reaped in the absence of infrastructure.

H3: Presence or absence of healthcare facility affects intention to purchase.

\section{Perceived costs}

The cost of insurance measured by the premium paid is perceived as the biggest barrier. Perhaps some of them even consider themselves to be anti-insurance (Martin et al., 2014). They reasoned paying for a health episode once, during its occurence is better than paying premiums repeatedly. Further young adults comparatively have lesser financial literacy and they spend more on automobiles, buying homes (Breitbach \& Walstad, 2016), and food and clothing (Levy \& DeLeire, 2009). Old age or retirement plans are hardly considered. Though lifestyle diseases such as cancer are surging yet ill health is associated with old age. Hence, purchasing a health cover might be considered as an additional cost when the perception of health status is positive. Further, when individuals are exposed to sickness, their income growth is slow during the revival period due to leave of absence. Perhaps the people who are exposed to sickness (illness) might perceive their income to be low compared to the ones that are non-exposed (non-illness). Thus, we hypothesised: 
H4: Perceived cost indicated by perception of low earnings, inability to bear medical expenses, basic necessities, and self-care affects purchase intention.

\section{Cue to Action}

In addition to the variants of health belief model, subjective norms, information, and trust on the insurer, knowledge about insurance and promotional strategies can also induce intention to purchase. Family has a significant influence on purchase decisions. Parents have considerable influence on their children and so do the siblings on each other (Cotte \& Wood, 2004). Even while parents do not possess health cover, they might influence their children to purchase one to avoid future contingency. With insurers introducing innovative products such as family floater policies that cover not only the individual but also the parents, spouse, and the children the scope has widened. Some of the family floater policies also cover the spouse's parents. In the event of a contingency to the elders, the coverage do come with co-insurance. Yet the insured is saved from incurring the full expense. However, social groups such as peer groups also influence behaviour. In developing countries, due to imbalanced geographic growth, migrating to the nearby towns or cities for education or career is prevalent. As the migration occurs at a young age the influence of the social group could perhaps be greater than the family itself. An individual when exposed to different environments exhibits different behaviours (Harris, 1995) that could be positive or negative. Perhaps there could be a desire to purchase a commodity that others do not possess it. Witnessing people undergo difficulty due to not possessing a product will itself act as a motivator for purchase. When they witness their family or friends experiencing a financial burden due to not possessing an insurance cover, they would not want to commit a similar mistake.

H5: Friends and family can positively or negatively impact purchase decision.

Trust on the context in which a business operates is pertinent. If the prospect has less confidence in the insurance regualtions then it would percolate on the insurer as well. Trust at various level plays a significant role. Interaction between the prospect or the insured occurs through the sales force such as the brokers or agents. The presence of web aggregators also is changing the way insurance products are purchased. Hence, seldom the interaction happens with the business organisation directly. Therefore, building trust at various levels becomes crucial (Grayson et al., 2008). Importantly, customers build trust by gathering information from various sources. The touch points being the broker, agent, online portal, or the insurance 
company. Hence, even if there is mistrust from one of these touch points it might affect the trust on the insurer itself.

H6: Trust on the insurer impacts willingness to buy.

With consumers gravitating towards online purchase, how significant is the physical presence of insurer? Previous studies have focused on tangible goods such as clothing (Kim \& Kim, 2004), groceries (Giri et al., 2020), etc. All these studies acknowledge the ease and convenience of online shopping. However, health insurance being highly intangible and completely based on uncertainty, this study seeks to find out whether physical presence such as office infrastructure is essential.

H7: Physical presence of the insurer impacts purchase intention.

Adverse selection due to information asymmetry is prevalent in insurance market. Presence of information gap between the insurer and the insured has been evidenced (Kim et al., 2009). To bridge this gap human intervention is essential. The terms and conditions in an insurance contract are either too technical or difficult to interpret for a common man. Human intervention through personal selling, either agents or brokers are most preferred means of promoting insurance products. Consumers who trust the agents continue to have long lasting insurance contracts. The agent undoubtedly have a greater influence on the consumers (Burnett \& Palmer, 1983). However, with the shift to online platforms, human touch in personal selling has also reduced. No longer do the agents approach the prospects personally. All information is sent through email or the prospects are asked to refer to the relevant websites for further clarification. The study seeks to find out if the agents become approachable, then will such a behaviour motivate purchase.

H8: Approachability of agents impacts purchase decision. 


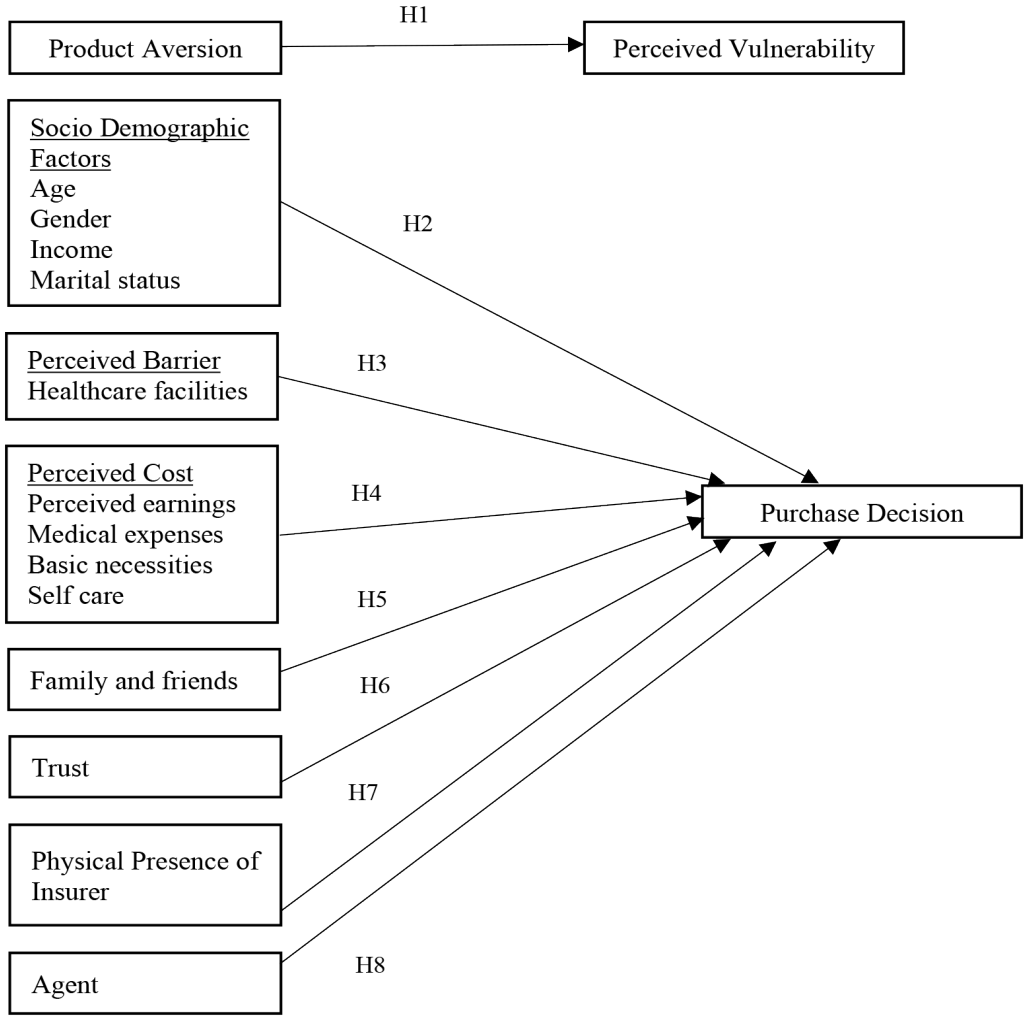

Figure 1. Conceptual framework of the study

\section{METHODOLOGY}

\section{Setting and Population}

Survey was carried out in four most populous districts in India that include, Trichy, Chennai, Tirunelveli, and Coimbatore. The sampling design was purposive. A total of 1,600 uninsured individuals were contacted through telephone calls to obtain their consent. Among them, 1,536 agreed to participate in the survey. After obtaining their consent, the survey instruments were mailed. As more than $50 \%$ of the population in each of these districts was not covered by health insurance, a proportion of $(50 \%)$ was fixed. The responses were collected only from those that were not a part of any insurance scheme. Hence, the respondents in this study did not possess any form of insurance. 


\section{Sample Size, Sampling, and Data Collection Procedure}

Cochran's formula was used to calculate the sample size. Accordingly,

$$
n_{0}=\frac{z^{2} p q}{e^{2}}, z=1.96, p=0.5, q=0.5, e=0.05
$$

This formula is used to calculate the sample size when the population is infinite, where $n_{0}$ represents the sample size; $z$ is the critical value, i.e., 1.96; $p$ is the proportion that is assumed to be present for a given variable in the population. As a usual practice, maximum variability of $50 \%$ is assumed. Hence $p$ is $50 \%(0.5)$ and $q$ is represented as $1-p(1-0.5=0.5)$; $e$ is the level of precision that is desired. Considering 95\% confidence level, precision level of 0.05 is set. After substituting in the formula, the calculated sample size is 384 . Hence, it was decided to collect 384 samples from each of the districts.

As per the formula, the total number of respondents should have been 1,536. Missing values were found in certain instruments. Therefore, we had to discard the unfilled survey instruments as they were not considered fit enough for further analysis. Only 1,339 instruments qualified for the study. Of the 1,339 respondents, 351 had encountered illness episodes (illness group) and 988 did not encounter any serious illness in the past year (non-illness group). The respondents had to either tick "yes" or "no" for the statement "have you or any of your members in the household have been diagnosed, treated, medicated, and/or monitored for any of the conditions listed in the table below in the last 1 year?" If yes, they had to further tick the listed non communicable disease. The list included chronic diseases such as HIV, congenital disease, cancer, kidney, brain, uterus, etc. This statement was included to counter check their response.

Table 1

Socio-demographic profiling of the respondents

\begin{tabular}{llrrrr}
\hline \multirow{2}{*}{ Variables } & & \multicolumn{2}{c}{ Illness } & \multicolumn{2}{c}{ Non-illness } \\
\cline { 3 - 6 } & & $\mathrm{F}$ & $\%$ & $\mathrm{~F}$ & $\%$ \\
\hline Age & $20-30$ years & 117 & 33 & 280 & 28 \\
& $31-40$ years & 149 & 42 & 354 & 36 \\
& $41-50$ years & 45 & 13 & 234 & 24 \\
& 51-60 years & 26 & 7 & 79 & 8 \\
Gender & Above 60 years & 14 & 4 & 41 & 4 \\
& Male & 190 & 54 & 405 & 41 \\
& Female & 161 & 46 & 583 & 59 \\
\hline
\end{tabular}


Table 1: (continued)

\begin{tabular}{llrrrr}
\hline \multirow{2}{*}{ Variables } & & \multicolumn{2}{c}{ Illness } & \multicolumn{2}{c}{ Non-illness } \\
\cline { 3 - 6 } & & F & $\%$ & F & $\%$ \\
\hline Marital Status & Bachelors & 77 & 22 & 224 & 23 \\
& Married & 246 & 70 & 645 & 65 \\
& Widow & 16 & 5 & 56 & 6 \\
& Widower & 7 & 2 & 35 & 4 \\
Income (INR) & Divorcee & 5 & 1 & 28 & 3 \\
& Less than 2,00,000 & 200 & 57 & 680 & 69 \\
& 2,00,000-5,00,000 & 110 & 31 & 227 & 23 \\
& $5,00,000-8,00,000$ & 32 & 9 & 75 & 8 \\
& $8,00,000-11,00,000$ & 7 & 2 & 3 & 0.3 \\
& Above 11,00,000 & 2 & 1 & 3 & 0.3 \\
\hline
\end{tabular}

\section{Independent Variables}

Perceived vulnerability is measured through the financial expenses incurred in the past one year due to occurrence of chronic disease for self or others in the family. The statement used to measure include "Over the last 12 months how much had you to pay for OOP expenses, that includes the doctor fee, surgery cost if any, lab test, medical expenses, etc." The respondents had to tick one of the following options. The options given to measure this statement were: "less than INR10,000" (coded as 1), "more than INR10,000-INR20,000" (coded as 2), "more than INR20,000INR30,000" (coded as 3), "more than INR30,000-INR40,000" (coded as 4), "more than INR40,000-INR50,000" (coded as 5), and "more than INR50,000" (coded as 6).

Perceived benefit was measured through the statements "My income is not sufficient to cover the medical cost incurred in the last one year," "Unable to bear medical expenses in the previous year," "Unable to meet basic necessities due to medical expenses incurred," and "Could not afford self-care due to increased household medical expenditure." The responses for these statements were recorded in a 5-point Likert scale ranging from strongly disagree (1) to strongly agree (5).

Perceived barriers were measured using the following statements "Do you have well established hospital facilities in your locality," "Do you have healthcare facility to detect all kinds of diseases," "Does the hospital in your locality charge high fee," and "Do you have primary or super specialty hospital in your locality." 


\section{VR Uma and VIlango}

These items were categorical in nature to be answered as "yes" (1) or "no" (0). Emotional barriers such as "do not want to buy," "do not feel the need," "save money instead," and "high premium" were also included. The responses for these statements were recorded in a 5-point Likert scale from strongly disagree (1) to strongly agree (5).

Cue to action was measured using the statements "Not taken by friends/relatives," "I know which insurer offers health insurance," "Presence of insurer in the locality," and "I trust the insurer." These items were also categorical in nature to be answered as "yes" (1) or "no" (0). Besides, statements to assess knowledge level and the impact of promotions were also included. These statements were measured in a 5-point Likert scale ranging from strongly disagree (1) to strongly agree (5). Socio-demographic variables such as age, gender, income, and marital status were also considered for analysis. These variables are considered independent as most of the health insurance policies are designed based on age, income, and gender or on the family size. Hence, socio-demographic variables are considered independent and not controlled.

\section{Dependent Variable}

Whether all the independent variable mentioned above would lead to the desired behaviour was measured through the statement "Are you willing to buy health insurance?" The response for this statement was recorded as "yes" (1) or "no" (0).

\section{Data Analysis}

Kendall's Tau-b correlation was used to test the relationship between product aversion and perceived vulnerability among the illness and non-illness groups. Product aversion was measured using the statement "Do not want to buy health insurance" in a 5-point Likert scale ranging from strongly disagree (1) to strongly agree (5). Logistic regression was used to find out the odds that socio-demographic, perceived severity, perceived cost, and perceived barriers will lead to purchase decision. The dependent variable was the willingness to purchase (1) or not to purchase health insurance $(0)$.

\section{Ethical Issues}

The respondents were contacted through telephone calls to obtain their consent. After obtaining their consent the survey instruments were mailed. Further, informed consent was taken from the respondents to fill the instrument. 


\section{RESULTS}

Among the illness group, inverse relationship exists between product aversion and perceived vulnerability $\mathrm{r}_{\mathrm{t}}(351)=-0.129, p<0.01$. As the perceived vulnerability increased incidental to increase in the OOP expenses due to medical reasons, it is seen that the aversion towards subscription of health insurance is reducing. Among the non-illness group, positive relationship exists between aversion and severity $\mathrm{r}_{\mathrm{t}}(988)=0.341, p<0.01$ (Table 2). Hence, H1 was accepted.

Table 2

Relationship between product aversion and perceived vulnerability

\begin{tabular}{|c|c|c|c|c|}
\hline & \multicolumn{2}{|c|}{ Illness } & \multicolumn{2}{|c|}{ Non-illness } \\
\hline & Aversion & Vulnerability & Aversion & Vulnerability \\
\hline Aversion & & & 1 & \\
\hline Vulnerability & & 1 & $0.341 * *$ & 1 \\
\hline
\end{tabular}

Table 3

Logistic regression analysis: Impact of variables predicting the purchase decision

\begin{tabular}{|c|c|c|c|c|}
\hline \multirow{2}{*}{ Predictors } & \multicolumn{2}{|c|}{ Illness } & \multicolumn{2}{|c|}{ Non-illness } \\
\hline & B & Wald & B & Wald \\
\hline Nagalkerke & \multicolumn{2}{|c|}{$\mathrm{R}=0.276$} & \multicolumn{2}{|c|}{$\mathrm{R}=0.151$} \\
\hline \multicolumn{5}{|l|}{ Socio-demographic } \\
\hline Age & -0.132 & 0.660 & $-0.183^{*}$ & 4.928 \\
\hline Gender & & 0.572 & & 0.318 \\
\hline Male & 0.878 & 0.402 & 0.310 & 0.188 \\
\hline Female & 0.994 & 0.495 & 0.357 & 0.250 \\
\hline Marital status & & 1.745 & & 5.388 \\
\hline Bachelor & 20.693 & 0.000 & -0.178 & 0.039 \\
\hline Married & 20.743 & 0.000 & -0.320 & 0.130 \\
\hline Widow & 19.717 & 0.000 & -0.959 & 1.044 \\
\hline Widower & 0.430 & 0.000 & -0.356 & 0.137 \\
\hline Divorcee & 0.037 & 0.030 & -1.032 & 0.955 \\
\hline Income & 0.241 & 2.884 & -0.201 & 2.867 \\
\hline \multicolumn{5}{|l|}{ Perceived barriers } \\
\hline Well-established hospital (present) & 0.339 & 1.194 & $0.735^{* *}$ & 12.375 \\
\hline Increased hospital charges (yes) & -0.529 & 1.802 & -0.242 & 2.328 \\
\hline
\end{tabular}


Table 3: (continued)

\begin{tabular}{lcccc}
\hline \multirow{2}{*}{ Predictors } & \multicolumn{2}{c}{ Illness } & \multicolumn{2}{c}{ Non-illness } \\
\cline { 2 - 5 } & B & Wald & B & Wald \\
\hline Healthcare facility for all diseases (present) & 0.715 & 3.587 & -0.226 & 1.477 \\
Primary and super specialty hospital (present) & $-0.845^{*}$ & 4.147 & 0.190 & 0.996 \\
Government takes preventive measures (yes) & 0.084 & 0.056 & 0.103 & 0.291 \\
Do not want to buy & $-0.388^{*}$ & 5.396 & $-0.27^{* *}$ & 8.461 \\
Do not feel the need & 0.059 & 0.133 & 0.120 & 2.353 \\
Save money instead & -0.004 & 0.001 & 0.010 & 0.014 \\
High premium & -0.081 & 0.358 & 0.114 & 2.265 \\
Perceived cost & & & & \\
Perception of low earnings & $-0.51^{* *}$ & 8.345 & $0.286^{* *}$ & 13.760 \\
Unable to bear medical expenses in the & 0.140 & 0.535 & $-0.232^{*}$ & 4.376 \\
previous year & & & & \\
Unable to meet basic necessities & -0.067 & 0.113 & 0.015 & 0.022 \\
Could not afford self-care & -0.631 & 1.720 & 0.081 & 0.496 \\
Cue to action & & & & \\
Not taken by friends/relatives & 0.648 & 1.907 & $-0.155^{*}$ & 5.643 \\
Trust on the insurer (yes) & -20.3 & 0.000 & -0.634 & 1.966 \\
Awareness about the insurer (present) & -0.348 & 0.776 & -0.002 & 0.000 \\
Presence of insurer in the locality (1) & 0.341 & 3.418 & 0.468 & 3.440 \\
No complete knowledge of insurance & 0.278 & 3.251 & 0.135 & 3.621 \\
Agents did not approach & -0.176 & 1.630 & 0.085 & 1.569 \\
$\chi^{2}$ & 6.549 & & 5.139 & \\
Df & 8 & & 8 & \\
\hline
\end{tabular}

Note: ${ }^{* *} p<0.01 ;{ }^{*} p<0.05$

\section{DISCUSSION}

Among the illness, perceived vulnerability was negatively correlated with product aversion. Increased healthcare costs due to occurrence of frequent or severe health episodes, reduced disinclination. However, the results do not indicate desire to purchase. This is evident from the weak correlation between perceived vulnerability and product aversion. It should be noted that perceived vulnerability alone does not lead to adoption of precautionary behaviour (Pligt, 1998) such as purchasing health insurance. Though they have been victimised previously due to illness, yet the risk exposure alone is not sufficient to induce them to purchase 
health insurance. Contrastingly, positive correlation was observed for the nonillness group. This group did not incur major health hazards in the past one year. Hence, the medical expenses incurred would have been comparatively lesser. It is obvious that the aversion remained high when correlated with vulnerability. Though the illness group acknowledge financial loss due to medical expenses in the past year, yet there is no strong predisposition towards purchase of health insurance product; even the non-illness group disfavoured the product. Perhaps, they feel less vulnerable and perceive the event to be controllable. Hence, other than perceived vulnerability, there are other factors that determine willingness to buy private health insurance.

Among the illness group, mere presence of primary and super-specialty hospitals in their locality will discourage them from purchasing health cover. The primary healthcare is just a first referral point and has limited treatment facilities. Similarly, the super-specialty hospitals also do not treat all the diseases. The illness group had learnt their lessons hard. By now they are very much aware that the primary and super-specialty hospitals are just not sufficient to treat all kinds of diseases. Among the non-illness, the presence of tertiary hospital will motivate them from purchasing health cover. Hence, there is a strong need for the presence of wellestablished or multi-specialty hospitals. A very high odds ratio compared to the other variables indicate the requirement for healthcare facility. The prospects require full feldged healthcare facilities. The results blatantly suggest that health insurance and medical care should not be viewed as two different sectors. The failure of healthcare system has a phenomenal effect on the insurance sector as well. In India, there are more than 30 non-life insurers, out of which 6 of them in the public and the rest from the private sector, that include 6 standalone health insurance companies. These standalone companies specifically deal with health insurance products. It should be noted that standalone companies are permitted to operate only in the health insurance sector. The government has been trying in all possibities to improve health insurance sector through privatisation and globalisation. Also the insurers strive to capture the market through various strategies such as providing tax benefits and riders. The study reveals the importance of the presence of well-estabilished healthcare facility at the vicinity of the prospect. Hence, all the marketing strategies and benefits offered in the absence of healthcare facility will be of no use. It just adds to the operation cost. The study also indicates that the presence of good hospitals at the vicinity reduces aversion to purchase health insurance cover. Hence, the absence of proper healthcare facility is the main barrier for penetration of health insurance.

Among the non-illness, the younger the age the higher the willingness to buy health insurance. The results contradict with previous studies (Hansen et al., 2016; 


\section{VR Uma and VIlango}

Onwujekwe et al., 2010) that find no significant differences in the risk attitudes among different age cohorts but corroborates with Ahmed et al . (2016) that reveals the trust by the older age group on being taken care by their grown up children perhaps acts as a deterrrent to purchase health insurance. Conversely, the younger adults do not enjoy such advantage, hence they are motivated to purchase health insurance. Therefore, the results suggest the growing need among the younger adults to buy. This is further reiterated by their income perception. The young adults under the non-illness category perceived their income to be sufficient enough to afford insurance. The results also indicate that among this category, there was no situation in the previous year that lead to exhorbitant expenditure due to illness episode. Conversely, the illness group perceived their income to be less to afford insurance. It is quite obvious that in the past year due to sickness, their healthcare cost had surged. Apparently, they would have met these expenses either through personal savings or assets or through debts. Needless to say, they would defnitely perceive their income to be less to afford insurance. Thus, we find contrasting perceptions between both the groups on their income levels. It should be noted here that the actual income was non significant among both the groups and did not impact willingness to buy. The fact that the previous year's sudden medical expense has caused a disruption in the illness group's savings or spending pattern has led them to believe that their income levels are low to afford insurance cover. Interestingly, major proportion of our respondents in both the categories earn below INR2,00,000. Therefore, it should be noted that more than the actual income, perception plays a vital role in determining willingness to buy.

The results also indicate that the non-illness group would prefer to purchase health insurance provided their friends or relatives possess one. Perhaps it acts as a cue to purchase. In India, the social systems such as family (or the extended family) plays a vital role in decision making. There is a strong sense of ingroup attitude towards their family and peer group (Sharma, 2015). Further, with private and corporate hospitals dominating the healthcare sector, the OOP expenses incurred is extremely huge. Millions of families become impoverished due to catastrophic health expenditure. Hence, witnessing such episodes and learning lessons out of these expereinces is not uncommon. Further, observing the experiences of their friends or family will lead to adoption of similar precautionary behaviour (Small \& Simonsohn, 2008).

\section{CONCLUSION}

The study clearly highlights the primary reason for underpenetration of health insurance market is the absence of adequate healthcare facilities. Establishing 
primary care or a super-specialty will not suffice. Multi-specialty hospitals should be established. Government must collaborate with corporate hospitals and work on a public-private partnership model. The ratio of participation between the public and private can be varied depending on the locations. Proportion of public sector participation should be higher in villages and small towns to ease the cost of medication. The study brings to light a very important dimension that one size does not fit all. Marketing strategies should be targeted considering two macro segments, the illness and the non-illness groups albeit the current sociodemographic segmentation pattern. Insurers should mainly target the pockets that have good healthcare access. Among the non-illness, insurers can target the younger adults, perhaps between 21 years to less than 40 years. Among the illness, since their perception of income is low due to medical expenses incurred, some strategies on the payment of premium should be introduced. It could be a discounted premium or staggered premium payments. This would motivate them to purchase the health cover. The catastrophic event in the past has led them to believe that their income is low to afford a health cover. The insurers can operate more through online platforms as their physical presence does not have any significant impact. This can decrease their operating cost and the benefit can be transferred to the insureds by reducing their premium. From the responses, it looks obvious that family and peers have an influence on the purchase decision. Perhaps, insurers may also consider promoting family floater and group policies on a larger scale.

\section{REFERENCES}

Ahmed, S., Hoque, M. E., Sarker, A. R., Sultana, M., Islam, Z., Gazi, R., \& Khan, A. M. (2016). Willingness-to-pay for community-based health insurance among informal workers in urban Bangladesh. PLOS ONE, 11(2), 1-16. https://doi. org/10.1371/journal.pone.0148211

Asgary, A., Willis, K., Taghvaei, A. A., \& Rafeian, M. (2004). Estimating rural households' willingness to pay for health insurance. The European Journal of Health Economics, 5(3), 209-215. https://doi.org/10.1007/s10198-004-0233-6

Asimakopoulou, G. K., Skinner, C. T., Spimpolo, J., Marsh, S., \& Fox, C. (2008). Unrealistic pessimism about risk of coronary heart disease and stroke in patients with type 2 diabetes. Patient Education and Counseling, 71(1), 95-101. https:// doi.org/10.1016/j.pec.2007.12.007

Bagarinao, T. R. (2016). Households' natural disaster preparedness: A view from a second class municipality in a developing country. Environment Asia, 9(2), 158-164.

Barati, M., \& Fariditavana, H. (2019). Technology progress and rising healthcare expenditure in the US. Applied Economics Letters, 27(6), 451-454. https://doi.or $\mathrm{g} / 10.1080 / 13504851.2019 .1631434$ 
Botzen, W. J., Aerts, J. C., \& Bergh, D. V. (2009). Willingness of homeowners to mitigate climate risk through insurance. Ecological Economics, 68(8-9), 22652277. https://doi.org/10.1016/j.ecolecon.2009.02.019

Branstrom, R., Kristjansson, S., \& Ullen, H. (2006). Risk perception, optimistic bias, and readiness to change sun related behaviour. European Journal of Public Health, 16(5), 492-497. https://doi.org/10.1093/eurpub/cki193

Breitbach, E., \& Walstad, B. W. (2016). Financial literacy and financial behavior among young adults in the United States. In E. Wuttke, J. Seifried, \& S. Schumann (Eds.), Economic competence and financial literacy of young adults (pp. 81-98). USA: Verlag Barbara Budrich. https://doi.org/10.2307/j.ctvbkk29d.7

Brown, L. S. (2007). Emotive health advertising and message resistance. Australian Psychologist, 36(3), 193-199. https://doi.org/10.1080/00050060108259655

Burnett, J. J., \& Palmer, A. B. (1983). Reliance on life insurance agents: A demographic and psychographic analysis of consumers. The Journal of Risk and Insurance, 50(3), 510-520. https://doi.org/10.2307/252446

Bush, J. P., \& Iannotti, J. R. (1990). A children's health belief model. Medical Care, 28(1), 69-86. https://doi.org/10.1097/00005650-199001000-00008

Cantania, A. C. (1984). The operant behaviourism of B. F. Skinner. The Behavioral and Brain Sciences, 7, 473-475. https://doi.org/10.1017/S0140525X00026728

Choudhary, L. M., Goswami, I. K., Khambhati, B. S., Shah, V., Makwana, N., \& Yadav, B. S. (2013). Awareness of health insurance and its related issues in rural areas of Jamnagar district. National Journal of Community Medicine, 4(2), 267-271.

Cotte, J., \& Wood, L. S. (2004). Families and innovative consumer behavior: A triadic analysis of sibling and parental influence. Journal of Consumer Research, 31(1), 78-86. https://doi.org/10.1086/383425

Duggal, R. (2012, September 1). Challenges in financing healthcare. Economic and Political Weekly, 47, 22-23.

Fenny, A. P., Yates, R., \& Thompson, R. (2018). Social health insurance schemes in Africa leave out the poor. International Health, 10(1), 1-3. https://doi. org/10.1093/inthealth/ihx046

Giri, A., Chatterjee, S., Biswas, S., \& Aich, A. (2020). Factors influencing consumer purchase intention of daily groceries through B2C websites in metro-cities of India. International Journal of Scientific and Technology Research, 9(1), 719722.

Goel, S. (2014). Health insurance: An empirical study of consumer behaviour in Rohtak district of Haryana. International Journal of Research in Management, Science \& Technology, 2(2), 2321-3264. https://doi.org/10.1509/jmkr.45.2.241

Grayson, K., Johnson, D., \& Chen, D. F. R. (2008). Is firm trust essential in a trusted environment? How trust in the business context influences customers. Journal of Marketing Research, 45(2), 241-256.

Gumber, A., Narayanan, L., \& Dhak, B. (2017). Rising healthcare costs and universal health coverage in India: An analysis of national sample surveys, 1986-2014. Ahmedabad: Gujarat Institute of Development Research. 
Hansen, V. J., Jacobsen, H. R., \& Lau, I. M. (2016). Willingness to pay for insurance in Denmark. The Journal of Risk and Insurance, 83(1), 49-76. https://doi. org/10.1111/j.1539-6975.2013.12011.x

Harris, J. R. (1995). Where is the child's environment? A group socialization theory of development. Psychological Review, 102(3), 458-89. https://doi. org/10.1037/0033-295X.102.3.458

Hochbaum, M. G. (1958). Research relating to health education. Health Education Monographs, 1(8), 10-21. https://doi.org/10.1177/109019816000100802

Islam, T., Sheikh, Z., Hameed, Z., Khan, I. U., \& Azam, R. I. (2018). Social comparison, materialism, and compulsive buying based on stimulus-response-model: A comparative study among adolescents and young adults. Young Consumers, 19(1), 19-37. https://doi.org/10.1108/YC-07-2017-00713

John, T. J. (2010, May 15-17). Is India ready for an overhaul in healthcare? Economic and Political Weekly, 45, 14-15.

Jung, J., \& Streeter, J. L. (2015). Does health insurance decrease health expenditure risk in developing countries? The cases of China. Southern Economic Journal, 82(2), 361-384. https://doi.org/10.1002/soej.12101

Kaestner, R., \& Lubotsky, D. (2016). Health insurance and income inequality. The Journal of Economic Perspectives, 30(2), 53-77. https://doi.org/10.1257/jep.30.2.53

Khan, M. (2010). Using the health belief model to understand pesticide use decisions. In The Pakistan development review, papers and proceedings PARTS I and II of The 26th Annual General Meeting and Conference of the Pakistan Society of Development Economists Islamabad. $49 / 4$ (pp. 941-956). Islamabad: Pakistan Institute of Development Economics. https://doi.org/10.30541/ v49i4IIpp.941-956

Kim, E. Y., \& Kim, Y.-K. (2004). Predicting online purchase intentions for clothing product. European Journal of Marketing, 38(7), 883-897. https://doi. org/10.1108/03090560410539302

Kim, H., Kim, D., Im, S., \& Hardin, W. J. (2009). Evidence of asymmetric information in the automobile insurance market: Dichotomous versus multinomial measurement of insurance coverage. The Journal of Risk and Insurance, 76(2), 342-366. https://doi.org/10.1111/j.1539-6975.2009.01302.x

King, B. J. (1983). Illness attributions and the health belief model. Health Education Quarterly, 10(3/4), 287-312. https://doi.org/10.1177/109019818301000309

Kirby, B. J., \& Kaneda, T. (2010). Unhealthy and uninsured: Exploring racial differences in health and health insurance coverage using a life table approach. Demography, 47(4), 1035-1051. https://doi.org/10.1007/BF03213738

Kirn, M. J. (1991). Religion and the health belief model. Journal of Religion and Health, 30(4), 321-329. https://doi.org/10.1007/BF00986903

Kirscht, P. J. (1974). The health belief model and personal health behaviour. Health Education Monograph, 2(4), 387-408. https://doi.org/10.1177/109019817400 200406 
Lam, S., Luerssen, G. T., Hadley, C., Daniels, B., Strickland, A. B., Brookshier, J., \& Pan, I. -W. (2017). The health belief model and factors associated with adherence to treatment recommendations for positional plagiocephaly. J Neurosurg Pediatr, 19, 282-288. https://doi.org/10.3171/2016.9.PEDS16278

Levy, H., \& DeLeire, T. (2009). What do people buy when they don't buy health insurance and what does that say about why they are uninsured? Inquiry, 45(4), 365-379. https://doi.org/10.5034/inquiryjrnl_45.04.365

Lin, Y., \& Grace, F. M. (2007). Household life cycle protection: Life insurance holdings, financial vulnerability, and portfolio implications. The Journal of Risk and Insurance, 74(1), 141-173. https://doi.org/10.1111/j.1539-6975.2007.00205.x

Maiman, A. L., \& Becker, H. M. (1974). The health belief model: Origins and correlates in psychological theory. Health Education Monographs, 2(4), 336-353. https:// doi.org/10.1177/109019817400200404

Majumdar, A., \& Borbora, S. (2013, October 19). Social security system and the informal sector in India: A review. Economic and Political Weekly, 48(42), 69-72.

Martin, T. L., Bharmal, N., Blanchard, C. J., Harvey, M., \& Williams, V. M. (2014). Barriers to health insurance coverage across Colorado. In T. L. Martin, N. Bharmal, C. J. Blanchard, M. Harvey, \& V. M. Williams (Eds.), Barriers to enrollment in health coverage in Colorado (pp. 9-18). Colorado: RAND Corporation. https://doi.org/10.7249/RR782

Mastrogiacomo, M., \& Alessie, R. (2014). The precautionary savings motive and household savings. Oxford Economic Papers, 66(1), 164-187. https://doi. org/10.1093/oep/gpt028

Noussair, N. C., Trautmann, T. S., \& Kuilen, V. D. (2014). Higher order risk attitudes, demographics and financial decisions. The Review of Economic Studies, 81(1), 325-355. https://doi.org/10.1093/restud/rdt032

Onwujekwe, E. O., Uzochukwu, S. B., Obikeze, N. E., Okoronkwo, I., Ochonma, G. O., Onoka, A. C., Madubuko, G., \& Okoli, C. (2010). Investigating determinants of out-of-pocket spending and strategies for coping with payments for healthcare in southeast Nigeria. BMC Health Services Research, 10(67), 1-10. https://doi. org/10.1186/1472-6963-10-67

Oyekale, A. S., \& Oyekale, T. O. (2010). Application of health belief model for promoting behaviour change among Nigerian single youth. African Journal of Reproductive Health, 14(2), 63-75.

Palm, R., \& Hodgson, M. E. (1992). After a California earthquake: Attitude and behaviour change. Chicago: University of Chicago Press.

Peters, H. E., Simon, K., \& Taber, R. J. (2014). Marital disruption and health insurance. Demography, 51(4), 1397-1421. https://doi.org/10.1007/s13524-014-0317-6

Pligt, J. v. d. (1998). Perceived risk and vulnerability as predictors of precautionary behaviour. British Journal of Health Psychology, 3, 1-14. https://doi. org/10.1111/j.2044-8287.1998.tb00551.x

Pol, G. L., Mueller, J. K., \& Adidam, T. P. (2000). Health insurance in the near elderly population. Population Research and Policy Review, 19(2), 97-112. https://doi. org/10.1023/A:1006441904583 
Raksanam, B., Taneepanichskul, S., Robson, G. M., \& Siriwong, W. (2014). Health risk behaviors associated with agrochemical exposure among rice farmers in a rural community, Thailand. Asia Pacific Journal of Public Health, 26(6), 588-595. https://doi.org/10.1177/1010539512466426

Sharma, D. S. (2018). Health care for India's 500 million: The promise of the national health protection scheme. Harvard Public Health Review, 18(Special Edition: Health in India), 1-14.

Sharma, S. (2015). Why Indians work: A cultural values perspective. Indian Journal of Industrial Relations, 50(3), 425-437.

Skinner, B. F. (1950). Are theories of learning necessary? The Psychological Review, 57(4), 193-216. https://doi.org/10.1037/h0054367

Small, A. D., \& Simonsohn, U. (2008). Friends of victims: Personal experience and prosocial behavior. Journal of Consumer Research, 35(3), 532-542. https://doi. org/10.1086/527268

Starr-McCluer, M. (1996). Health insurance and precautionary savings. The American Economic Review, 86(1), 285-295.

Stein, A. J., Fox, A. S., Murata, J. P., \& Morisky, E. D. (1992). Mammography usage and the health belief model. Health Education Quarterly, 19(4), 447-462. https://doi. org/10.1177/109019819201900409

Sundaran, M. S. (2012). TB control progamme in Tamil Nadu: A historical perspective from 2000-2010. Proceedings of the Indian Histroy Congress, 73, 1404-1411.

Sung, J. Y., Choi, Y. P., Chan, K. L., Ching, Y. L., Lau, T. F., \& Griffiths, S. (2008). Obstacles to colorectal cancer screening in Chinese: A study based on the health belief model. American Journal of Gastroenterology, 103, 974-981. https://doi. org/10.1111/j.1572-0241.2007.01649.x

Tirgil, A., Dickens, W., \& Atun, R. (2019). Effects of expanding a non-contributory health insurance scheme on out-of-pocket healthcare spending by the poor in Turkey. BMJ Global Health, 4(4). 1-10. https://doi.org/10.1136/bmjgh-2019-001540

Varkey, P., Kureshi, S., \& Lesnick, T. (2010). Empowerment of women and its association with the health of the community. Journal of Women's Health, 19(1), 71-76. https://doi.org/10.1089/jwh.2009.1444

Weinstein, D. N. (1989). Optimistic biases about personal risks. Perspectives, 246(4935), 1232-1233. https://doi.org/10.1126/science.2686031

Yoon, C., Cole, A. C., \& Lee, P. M. (2009). Consumer decision making and aging: Current knowledge and future directions. Journal of Consumer Psychology, 19(1), 2-16. https://doi.org/10.1016/j.jcps.2008.12.002

Yoon, C., Laurent, G., Fung, H. H., Gonzalez, R., Gutchess, H. A., Hedden, T., LambertPandraud, R., Mather, M., Park, D., Peters, E., \& Skurnik, I. (2005). Cognition, persuasion and decision making in older consumers. Marketing Letters, 16(3/4), 429-441. https://doi.org/10.1007/s11002-005-5903-3

Zhao, J., Zheng, Z., Han, X., Davidoff, J. A., Banegas, P. M., Rai, A., Jemal, A., \& Yabroff, K. R. (2019). Cancer history, health insurance coverage, and costrelated medication nonadherence and medication cost-coping strategies in the United States. Value in Health, 22(7), 762-767. https://doi.org/10.1016/j. jval.2019.01.015 